\title{
Efeito da condição corporal ao parto sobre a produção e composição do leite, a curva de lactação e a mobilização de reservas corporais em vacas da raça Holandesa
}

\author{
[Effects of body condition at calving on milk yield and composition, lactation \\ curve and body reserve mobilization of Holstein cows]

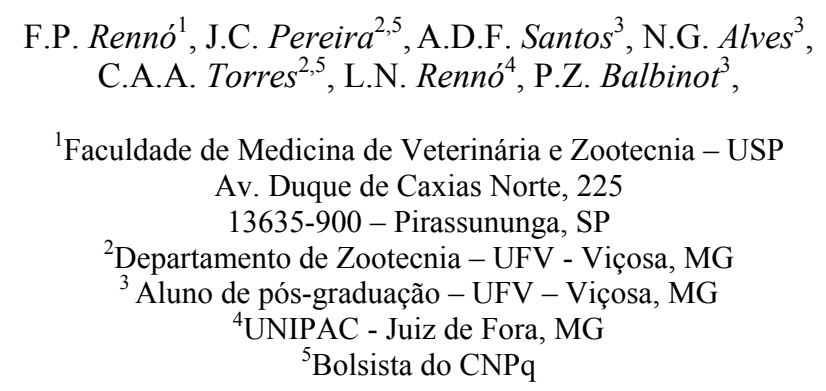

\section{RESUMO}

Avaliaram-se os efeitos do escore da condição corporal ao parto sobre a produção e composição do leite, a curva de lactação e o padrão de mobilização de reservas corporais em vacas da raça Holandesa. Foram utilizadas 51 vacas, sendo 13 primíparas e 38 multíparas, distribuídas em delineamento inteiramente ao acaso, segundo a ordem de partos - primíparas e multíparas - e a classe de escore da condição corporal ao parto (ECCP) - classe 1 ECCP igual ou superior a 3,25, e classe 2 ECCP igual ou inferior a 3,0. Para avaliar o padrão de mobilização de reservas corporais, foram formados grupos de vacas em função do ECCP e do nível de produção de leite. Nas primíparas, não foram observados efeitos da ECCP sobre a produção e a composição do leite e sobre a curva da lactação, exceto para porcentagem de gordura. Nas multíparas, as vacas da classe 1 produziram mais leite e mais componentes do leite, e a curva da lactação mostrou pico de produção mais alto. As vacas de maior ECCP e maior produção de leite apresentaram padrão de mobilização de reservas corporais mais acentuado no início da lactação e maior peso corporal no pré-parto e ao parto. O peso corporal e a mudança de peso corporal ao parto e no início da lactação não foram influenciados pelo escore de condição corporal ao parto e pela produção de leite.

Palavras-chave: gado de leite, curva de lactação, escore corporal, produção de leite, composição do leite

\begin{abstract}
The effects of body condition at calving on milk yield, milk composition, lactation curve and body tissue mobilization patterns were evaluated in Holstein cows. Thirteen primiparous and 38 multiparous cows were assigned body condition scores at calving (BCC). Those with BCC equal to or greater than 3.25 were assigned to class 1; while those with BCC less than 3.25 constituted class 2 . These BCC classes did not affect milk yield, milk composition (except for fat percentage) or lactation curve significantly in primiparous cows. In multiparous cows, however, class 1 individuals had higher total milk yield, higher peak milk yield, higher milk composition percentages and more effective mobilization of body tissue reserves than cows in class 2. Among those cows that had higher BCC, those with more effective mobilization of body tissue reserves at the beginning of lactation had higher milk yields. Cows with higher BCC were heavier at prepartum and at calving in comparison to cows with lower BCC. However,
\end{abstract}

Recebido em 14 de agosto de 2003

Aceito em 23 de agosto de 2005

E-mail: fprenno@hotmail.com 
body weight at calving and change in body weight early in lactation were not related to body composition at calving and subsequent milk yield.

Keywords: dairy cow, body score, lactation curve, milk yield, milk composition

\section{INTRODUÇÃO}

Vacas leiteiras apresentam constantes alterações na composição corporal durante a lactação e no período seco, refletindo, primariamente, a mobilização ou reposição de tecidos corporais quando as dietas contêm energia insuficiente ou em excesso para o atendimento das exigências nutricionais (Komaragiri et al., 1998). Durante a lactação, as exigências nutricionais de energia são atendidas por uma combinação dos nutrientes fornecidos na dieta e pela mobilização de reservas corporais (Butler e Smith, 1989). Os tecidos corporais envolvidos (principalmente tecido adiposo interno e externo) são comumente denominados de reservas corporais (Nutrient..., 2001).

Segundo Bauman e Currie (1980), no primeiro mês de lactação, as reservas corporais podem contribuir com cerca de $33 \%$ da produção de leite. A mobilização, principalmente do tecido adiposo, pode suportar produção de 120 a $550 \mathrm{~kg}$ de leite durante as primeiras semanas da lactação (Tamminga et al., 1997). Essa contribuição é reflexo da maior atividade lipolítica e da menor atividade lipogênica no tecido adiposo no início de lactação, o que se deve a mudanças endócrinas e hormonais características desse período (Bell, 1995).

A atividade lipolítica no tecido adiposo é regulada por diversos fatores. Entre eles destacam-se o escore de condição corporal (ECC) ao parto, que representa a quantidade de reservas corporais retida no corpo do animal, e a produção de leite, que se relaciona à magnitude dos estímulos hormonais que regulam as taxas de lipólise e lipogênese, bem como a partição de nutrientes entre a glândula mamária e o restante dos tecidos corporais (Herdt, 2000).

Segundo Waltner et al. (1993), o monitoramento adequado das reservas corporais é crítico para a manutenção de vacas leiteiras, principalmente de alta produção, em condições de expressarem seu potencial produtivo. Quando as vacas estão muito gordas ou muito magras ao parto, apresentam maior risco de desenvolverem desordens metabólicas e demais doenças, de apresentarem baixa produção de leite, pobre desempenho reprodutivo, dificuldade de parto e grande mobilização de reservas corporais pósparto.

O método de avaliação de reservas corporais por meio do ECC, apesar da natureza subjetiva, é a única forma prática de avaliação de reservas corporais em vacas leiteiras (Nutrient..., 2001). O ECC é um método aceitável, não invasivo, rápido e de baixo custo para estimar a quantidade de reservas corporais em vacas leiteiras (Waltner et al., 1993).

Waltner et al. (1993) verificaram que o ECC influenciou a produção de leite aos 90 dias de lactação, sendo as maiores produções de leite observadas em vacas que apresentaram o ECC ao parto (ECCP) entre 3,0 e 4,0. Domecq et al. (1997) estimaram que maior ECCP resultou em cerca de mais $545 \mathrm{~kg}$ de leite nos primeiros 120 dias de lactação, elevando também a produção de gordura. Urban e McGilliard (1990) verificaram resultados semelhantes, em que o ECCP foi importante fonte de variação na produção de leite de vacas de média e alta produção. Outros autores, no entanto, verificaram que o ECCP não influenciou a produção de leite obtida na própria lactação (Pedron et al., 1993; Santos, 1996; Lago et al., 2001).

Pedron et al. (1993) avaliaram vacas de diferentes ECCP e verificaram que a mobilização de reservas corporais no início da lactação influenciou a curva de lactação. Vacas com maior $\operatorname{ECCP}(>3,0)$ apresentaram curvas de lactação com maior pico de produção e persistência de lactação comparando-se com vacas de menor ECCP. Segundo Bell (1995) e Goff (2004), vacas com maior ECCP tendem a apresentar maior produção de leite em função da grande contribuição das reservas corporais no fornecimento de nutrientes para a síntese de leite e de seus componentes.

Variações no ECC durante a lactação, refletindo o padrão de mobilização de reservas corporais, estão relacionadas com os dias em lactação, 
sendo esperada uma diminuição gradativa no ECC no início da lactação, seguida de posterior recuperação e retorno ao ECC inicial no meio e final da lactação (Pedron et al., 1993; Waltner et al., 1993). Entretanto, a influência do ECCP e a do nível de produção de leite sobre a magnitude dos efeitos lipolíticos e lipogênicos nos diversos tecidos corporais, pré e pós-parto, têm resultado em variações no padrão de mobilização de reservas corporais, com vacas de maior ECCP, de alta produção de leite e multíparas, apresentando maiores variações no ECC no início da lactação (Gallo et al., 1996).

O peso corporal também apresenta variações durante a lactação. Ele é influenciado pelo tamanho dos animais (desenvolvimento de esqueleto), quantidade de reservas corporais e enchimento do trato gastrintestinal (Enevoldsen e Kristensen, 1997), fatores esses dependentes dos estádios de lactação e gestação e da idade dos animais (Koenen et al., 1999). Segundo Koenen et al. (1999) e Buckley et al. (2000), o peso corporal (PC) segue um padrão com rápida diminuição ao parto, coincidindo com a expulsão do feto, da placenta e dos demais conteúdos uterinos, acompanhado pelo declínio gradual do peso em razão da mobilização de reservas corporais para o fornecimento de energia para a produção de leite. Após o início da lactação e nova concepção, há retorno ao peso inicial em função da reposição dos tecidos corporais mobilizados e do desenvolvimento fetal.

A variação do peso corporal no início da lactação pode estar relacionada à produção de leite e ao ECCP (Tamminga et al., 1997). Holter et al. (1990) e Berry et al. (2002) avaliaram o peso corporal no início da lactação de vacas com diferentes ECCP e verificaram que vacas com maior ECCP apresentaram maior redução de peso pós-parto, com o peso corporal atingindo seu menor valor próximo a 40 dias pós-parto. No entanto, Santos (1996) não verificou diferenças em relação à mudança de peso em vacas de diferentes ECCP, e Aeberhard et al. (2001), que avaliaram vacas de alta e média produção, não verificaram diferenças na mudança de peso ao longo da lactação nos diferentes níveis de produção.

Os objetivos deste estudo foram estudar os efeitos da condição corporal ao parto sobre a produção e a composição do leite e sobre a curva de lactação e avaliar os efeitos da condição corporal ao parto e do nível de produção de leite sobre o padrão de mobilização de reservas corporais e peso corporal, em vacas da raça Holandesa.

\section{MATERIAL E MÉTODOS}

O estudo foi realizado entre abril de 2002 e março de 2003. Utilizaram-se 51 vacas da raça Holandesa (de 7/8 Holandês-Zebu até puras de origem), 13 primíparas e 38 multíparas, avaliadas desde 30 dias antes do parto até 150 dias pósparto.

Os animais foram alojados em estábulo tipo freestall, alimentados duas vezes ao dia, à vontade, na forma de dieta total, com a ração formulada segundo o NRC (Nutrient..., 2001). Utilizaram-se silagem de milho como volumoso e mistura de milho triturado, farelo de soja, farelo de trigo, farelo de algodão, uréia, minerais e vitaminas como concentrado. As vacas foram ordenhadas por ordenhadeira mecânica, duas vezes ao dia.

A mensuração do ECCP foi realizada segundo metodologia proposta por Wildman et al. (1982), desenvolvida por Edmonson et al. (1989). Baseia-se em avaliações visuais e táteis das reservas corporais em pontos específicos do corpo da vaca, adotando-se uma escala biológica de 1 a 5 , com subunidades de 0,25 pontos, em que 1 representa a vaca muito magra e 5, a muito gorda, independente do peso corporal ou do tamanho (altura, perímetro toráxico, comprimento) (Wildman et al., 1982; Edmonson et al., 1989).

Os animais foram pesados semanalmente e no dia do parto (nas primeiras 24 horas pós-parto). A produção de leite foi medida a cada sete dias. Amostras de leite foram coletadas quinzenalmente para avaliação da porcentagem de gordura e dos extratos seco total e desengordurado. A produção de leite foi corrigida para $3,5 \%$ de gordura, segundo Sklan et al. (1994).

Utilizou-se delineamento inteiramente ao acaso, com os animais classificados segundo a ordem de parto em primíparas e multíparas (vacas de dois ou mais partos), distribuídos em duas classes de ECCP: classe 1, vacas com ECCP igual ou superior a 3,25 , e classe 2 , vacas com 
ECCP igual ou inferior a 3,0. As classes de ECCP diferiram $(\mathrm{P}<0,01)$ em relação a suas médias $(3,41$ e 2,86 para primíparas, com 6 e 7 repetições, e 3,44 e 2,77 para multíparas, com 18 e 20 repetições, respectivamente, para as classes 1 e 2). Foram realizadas análises distintas para as vacas primíparas e multíparas.

Para a avaliação do padrão de mobilização de reservas corporais, foi mensurada a variação do escore de condição corporal (MECC). Além de ser considerada a classe de ECCP, foi utilizado o nível de produção de leite corrigido até os 150 dias de lactação na avaliação da MECC, sendo formadas duas classes: níveis alto (A) e médio (M) de produção para vacas primíparas e multíparas. Os animais foram considerados de alta produção quando a produção média de leite corrigida foi igual ou superior a 21,0 e $29,0 \mathrm{~kg} / \mathrm{dia}$, respectivamente, para vacas primíparas e multíparas. Dessa forma, formaramse quatro grupos: classe 1 e nível alto de produção (grupo AA), classe 1 e nível médio de produção (grupo AM), classe 2 e nível alto de produção (grupo BA) e classe 2 e nível médio de produção (grupo $\mathrm{BM}$ ), para primíparas e multíparas.

$\mathrm{O}$ peso corporal (PC) e a variação do peso corporal (MPC) foram avaliados agrupando as vacas primíparas e multíparas em uma única classe de idade. Os períodos estudados foram 1) pré-parto - mudança de peso desde 20 até três dias pré-parto; 2) parto - mudança de peso desde três dias pré-parto até o dia do parto (primeiras 24 horas pós-parto); e 3) período pós-parto mudança de peso desde o dia do parto até 150 dias pós-parto. Os animais foram avaliados em grupos formados para a avaliação da MECC.

As variáveis produção de leite (PL), produção de leite corrigida para $3,5 \%$ de gordura (PLC), produção $(\mathrm{Gkg})$ e porcentagem $(\mathrm{G} \%)$ de gordura, produção (ESTkg) e porcentagem $(\mathrm{EST} \%)$ de extrato seco total, produção (ESDkg) e porcentagem $(\mathrm{ESD} \%)$ de extrato seco desengordurado, escore de condição corporal (ECC) e mudança de condição corporal (MECC) (em relação ao ECCP), peso corporal (PC) e mudança de peso corporal (MPC), nos diferentes períodos, foram analisadas pelo procedimento PROC MIXED do SAS (User's..., 1999), utilizando modelo linear misto para medidas repetidas no tempo. Esse procedimento permitiu melhor ajuste na estrutura da matriz que descreve as covariâncias de medidas repetidas no tempo.

Na avaliação da PL, PLC, Gkg, G\%, ESTkg, $\mathrm{EST} \%$, ESDkg e ESD\%, foram considerados os efeitos fixos de classe de ECCP os dias em lactação e a interação classe de ECCP $\times$ dias em lactação. Na avaliação do ECC, MECC, PC e $\mathrm{MPC}$, foram considerados os efeitos fixos de grupo (ECCP $\times$ nível de produção de leite), os dias em lactação e a interação grupo $\times$ dias em lactação. Os efeitos de animal dentro de classes e de grupos foram considerados aleatórios.

Para PC e MPC, por serem analisadas em conjunto, primíparas e multíparas, a ordem de partos foi incluída como covariável quando significativa ao nível de $5 \%$ de probabilidade. Em função das diferenças no peso corporal no início do período experimental, o peso aos 20 dias pré-parto e o peso após o parto foram utilizados como covariáveis para a avaliação da MPC nos períodos pré e pós-parto, respectivamente.

A curva de lactação foi avaliada segundo a classe de ECCP utilizando análises de regressão. Foram avaliadas a PL, a PLC e a G\% em função dos dias em lactação, nas vacas primíparas e multíparas. Para a avaliação do período de menor ECC e PC durante o período pós-parto, foram realizadas análises de regressão do $\mathrm{ECC}$ e do PC em função dos dias de lactação. Para a análise desses dados, foi utilizado o procedimento PROC REG do SAS (User's..., 1999).

\section{RESULTADOS E DISCUSSÃO}

O resumo das análises de variância da PL, PLC, Gkg e G\%, ESTkg e EST\%, ESDkg e ESD\% pode ser observado na Tab. 1. Nas Tab. 2 e 3 são apresentadas as médias da PL e PLC, segundo a classe de ECCP, para vacas primíparas e multíparas. Nas primíparas, não foi observado efeito do ECCP sobre a PL $(\mathrm{P}>0,05)$ e a PLC $(\mathrm{P}>0,05)$. Nas multíparas, foi observado efeito do ECCP sobre a PL $(\mathrm{P}<0,05)$ e a PLC $(\mathrm{P}<0,05)$, especialmente quando as médias de produção foram avaliadas a partir dos 45 dias de lactação. As vacas multíparas da classe $1 \quad(\mathrm{ECCP} \geq 3,25)$ apresentaram a PL e a PLC aos 150 dias de lactação, respectivamente, 19,6 e $19,9 \%$ superiores às da classe $2(\mathrm{ECCP}<3,25)$. 
Tabela 1. Nível de significância dos fatores incluídos nas análises de variância da produção de leite (PL), produção de leite corrigida para $3,5 \%$ de gordura (PLC), produção (Gkg) e porcentagem $(\mathrm{G} \%)$ de gordura, produção (ESTkg) e porcentagem (EST\%) de extrato seco total e produção (ESDkg) e porcentagem (ESD\%) de extrato seco desengordurado, nas vacas primíparas e multíparas

\begin{tabular}{|c|c|c|c|c|c|c|c|c|}
\hline \multirow{2}{*}{ Variável } & \multicolumn{8}{|c|}{ Valor de $\mathrm{P}$} \\
\hline & PL & PLC & Gkg & $\mathrm{G} \%$ & ESTkg & EST $\%$ & ESDkg & $\mathrm{ESD} \%$ \\
\hline & \multicolumn{8}{|c|}{ Primíparas } \\
\hline Classe $^{1}$ & 0,5472 & 0,1703 & 0,0968 & 0,0268 & 0,3690 & $\mathbf{0 , 0 5 5 2}$ & 0,5976 & 0,9239 \\
\hline Tempo $^{2}$ & $<0,0001$ & $<0,0001$ & $<0,0001$ & 0,1011 & $<0,0001$ & $<0,0001$ & $<0,0001$ & 0,1182 \\
\hline \multirow[t]{2}{*}{ Classe $\mathrm{x}$ tempo } & 0,5553 & 0,7045 & 0,1126 & 0,2510 & 0,0028 & 0,1039 & 0,2382 & 0,2469 \\
\hline & \multicolumn{8}{|c|}{ Multíparas } \\
\hline Classe & 0,0488 & $\mathbf{0 , 0 2 5 3}$ & 0,0121 & 0,7292 & $\mathbf{0 , 0 2 5 7}$ & 0,3262 & 0,0559 & 0,0062 \\
\hline Tempo & $<0,0001$ & $<0,0001$ & $<0,0001$ & 0,0897 & $<0,0001$ & 0,0307 & $<0,0001$ & 0,0358 \\
\hline Classe $\mathrm{x}$ tempo & 0,0284 & 0,0267 & 0,0138 & 0,1929 & 0,0737 & 0,3943 & 0,2643 & 0,0965 \\
\hline
\end{tabular}

Tabela 2. Produção de leite (PL), produção de leite corrigida a 3,5\% de gordura (PLC), produção de gordura $(\mathrm{Gkg})$, porcentagem de gordura $(\mathrm{G} \%)$, produção de extrato seco total (ESTkg), porcentagem de extrato seco total (EST\%), produção de extrato seco desengordurado (ESDkg) e porcentagem de extrato seco desengordurado (ESD\%), segundo os dias de lactação e a classe de escore de condição corporal ao parto, nas vacas primíparas

\begin{tabular}{|c|c|c|c|c|c|c|c|c|c|c|c|}
\hline \multirow{2}{*}{ Item } & \multirow{2}{*}{ Classe } & \multicolumn{10}{|c|}{ Dias de lactação } \\
\hline & & 15 & 30 & 45 & 60 & 75 & 90 & 105 & 120 & 135 & 150 \\
\hline \multirow{3}{*}{$\begin{array}{l}\mathrm{PL} \\
(\mathrm{kg} / \mathrm{d})\end{array}$} & $1^{1}$ & 22,50 & 22,31 & 22,38 & 22,16 & 22,08 & 21,85 & 21,45 & 21,03 & 20,78 & 20,48 \\
\hline & $2^{2}$ & 20,53 & 20,20 & 20,48 & 20,44 & 20,38 & 20,17 & 20,08 & 19,92 & 19,78 & 19,52 \\
\hline & $P<^{3}$ & 0,434 & 0,382 & 0,471 & 0,517 & 0,521 & 0,524 & 0,614 & 0,687 & 0,717 & 0,724 \\
\hline \multirow{3}{*}{$\begin{array}{l}\text { PLC } \\
(\mathrm{kg} / \mathrm{d})\end{array}$} & 1 & 24,61 & 24,33 & 23,98 & 23,56 & 23,21 & 22,95 & 22,66 & 22,41 & 22,15 & 21,83 \\
\hline & 2 & 20,37 & 19,65 & 19,95 & 19,90 & 19,88 & 19,61 & 19,48 & 19,27 & 19,18 & 18,98 \\
\hline & $P<$ & 0,104 & 0,063 & 0,133 & 0,169 & 0,209 & 0,207 & 0,239 & 0,257 & 0,283 & 0,295 \\
\hline \multirow{3}{*}{$\begin{array}{l}\mathrm{Gkg} \\
(\mathrm{kg} / \mathrm{d})\end{array}$} & 1 & 0,914 & 0,887 & 0,804 & 0,753 & 0,753 & 0,783 & 0,792 & 0,765 & 0,739 & 0,700 \\
\hline & 2 & 0,705 & 0,636 & 0,700 & 0,675 & 0,678 & 0,613 & 0,629 & 0,593 & 0,652 & 0,591 \\
\hline & $P<$ & 0,044 & 0,022 & 0,058 & 0,074 & 0,109 & 0,103 & 0,108 & 0,117 & 0,131 & 0,135 \\
\hline \multirow{3}{*}{$\mathrm{G} \%(\%)$} & 1 & 4,05 & 4,04 & 3,94 & 3,89 & 3,80 & 3,80 & 3,84 & 3,88 & 3,88 & 3,89 \\
\hline & 2 & 3,48 & 3,36 & 3,35 & 3,35 & 3,35 & 3,33 & 3,32 & 3,29 & 3,32 & 3,33 \\
\hline & $P<$ & 0,080 & 0,031 & 0,044 & 0,048 & 0,067 & 0,047 & 0,032 & 0,020 & 0,019 & 0,016 \\
\hline \multirow{3}{*}{$\begin{array}{l}\text { ESTkg } \\
(\mathrm{kg} / \mathrm{d})\end{array}$} & 1 & 2,877 & 2,854 & 2,793 & 2,675 & 2,590 & 2,572 & 2,437 & 2,333 & 2,377 & 2,235 \\
\hline & 2 & 2,489 & 2,356 & 2,486 & 2,469 & 2,397 & 2,255 & 2,325 & 2,280 & 2,335 & 2,157 \\
\hline & $P<$ & 0,233 & 0,152 & 0,224 & 0,274 & 0,311 & 0,308 & 0,372 & 0,434 & 0,482 & 0,503 \\
\hline \multirow{3}{*}{$\begin{array}{l}\text { EST\% } \\
(\%)\end{array}$} & 1 & 12,74 & 12,81 & 12,70 & 12,62 & 12,49 & 12,46 & 12,51 & 12,54 & 12,54 & 12,55 \\
\hline & 2 & 12,15 & 12,02 & 11,95 & 12,03 & 12,01 & 11,99 & 11,98 & 11,99 & 12,05 & 12,10 \\
\hline & $P<$ & 0,149 & 0,034 & 0,025 & 0,051 & 0,123 & 0,111 & 0,100 & 0,080 & 0,093 & 0,096 \\
\hline \multirow{3}{*}{$\begin{array}{l}\text { ESDkg } \\
(\mathrm{kg} / \mathrm{d})\end{array}$} & 1 & 1,965 & 1,965 & 1,959 & 1,872 & 1,839 & 1,787 & 1,648 & 1,562 & 1,641 & 1,539 \\
\hline & 2 & 1,783 & 1,723 & 1,783 & 1,795 & 1,719 & 1,642 & 1,695 & 1,691 & 1,681 & 1,564 \\
\hline & $P<$ & 0,444 & 0,351 & 0,401 & 0,465 & 0,481 & 0,484 & 0,584 & 0,688 & 0,740 & 0,768 \\
\hline \multirow{3}{*}{$\begin{array}{l}\text { ESD\% } \\
(\%)\end{array}$} & 1 & 8,69 & 8,77 & 8,76 & 8,73 & 8,68 & 8,66 & 8,66 & 8,65 & 8,65 & 8,66 \\
\hline & 2 & 8,67 & 8,67 & 8,60 & 8,68 & 8,66 & 8,65 & 8,65 & 8,70 & 8,73 & 8,76 \\
\hline & $P<$ & 0,923 & 0,552 & 0,287 & 0,677 & 0,879 & 0,967 & 0,968 & 0,799 & 0,634 & 0,503 \\
\hline
\end{tabular}

${ }^{1}$ Classe 1: escore de condição corporal ao parto $\geq 3,25$ (média ECCP=3,41).

${ }^{2}$ Classe 2: escore de condição corporal ao parto $<3,25$ (média $\mathrm{ECCP}=2,85$ ).

${ }^{3}$ Nível de significância. 
Tabela 3. Produção de leite (PL), produção de leite corrigida a 3,5\% de gordura (PLC), produção de gordura $(\mathrm{Gkg})$, porcentagem de gordura $(\mathrm{G} \%)$, produção de extrato seco total (ESTkg), porcentagem de extrato seco total (EST\%), produção de extrato seco desengordurado (ESDkg) e porcentagem de extrato seco desengordurado (ESD\%), segundo os dias de lactação e a classe de escore de condição corporal ao parto, nas vacas multíparas

\begin{tabular}{|c|c|c|c|c|c|c|c|c|c|c|c|}
\hline \multirow{2}{*}{ Item } & \multirow{2}{*}{ Classe } & \multicolumn{10}{|c|}{ Dias de lactação } \\
\hline & & 15 & 30 & 45 & 60 & 75 & 90 & 105 & 120 & 135 & 150 \\
\hline \multirow{3}{*}{$\begin{array}{l}\mathrm{PL} \\
(\mathrm{kg} / \mathrm{d})\end{array}$} & $1^{1}$ & 30,65 & 32,47 & 33,46 & 33,66 & 33,73 & 33,62 & 33,28 & 32,68 & 32,05 & 31,31 \\
\hline & $2^{2}$ & 28,45 & 29,07 & 29,28 & 29,10 & 28,88 & 28,48 & 27,95 & 27,43 & 26,82 & 26,17 \\
\hline & $P<^{3}$ & 0,397 & 0,192 & 0,097 & 0,062 & 0,040 & 0,026 & 0,017 & 0,016 & 0,015 & 0,015 \\
\hline \multirow{3}{*}{$\begin{array}{l}\text { PLC } \\
(\mathrm{kg} / \mathrm{d})\end{array}$} & 1 & 32,12 & 33,31 & 34,23 & 34,25 & 34,28 & 34,18 & 33,89 & 33,26 & 32,61 & 31,87 \\
\hline & 2 & 29,43 & 29,87 & 29,78 & 29,22 & 28,73 & 28,46 & 28,09 & 27,69 & 27,19 & 26,58 \\
\hline & $P<$ & 0,308 & 0,183 & 0,080 & 0,036 & 0,014 & 0,007 & 0,005 & 0,005 & 0,006 & 0,005 \\
\hline \multirow{3}{*}{$\begin{array}{l}\text { Gkg } \\
(\mathrm{kg} / \mathrm{d})\end{array}$} & 1 & 1,158 & 1,207 & 1,275 & 1,199 & 1,207 & 1,189 & 1,143 & 1,018 & 0,967 & 0,883 \\
\hline & 2 & 1,050 & 1,073 & 1,029 & 0,934 & 0,901 & 0,961 & 0,925 & 0,901 & 0,843 & 0,761 \\
\hline & $P<$ & 0,300 & 0,231 & 0,107 & 0,042 & 0,014 & 0,007 & 0,005 & 0,005 & 0,006 & 0,007 \\
\hline \multirow{3}{*}{$\mathrm{G} \%(\%)$} & 1 & 3,84 & 3,71 & 3,67 & 3,63 & 3,63 & 3,63 & 3,64 & 3,64 & 3,64 & 3,64 \\
\hline & 2 & 3,71 & 3,70 & 3,62 & 3,54 & 3,49 & 3,53 & 3,56 & 3,59 & 3,62 & 3,63 \\
\hline & $P<$ & 0,566 & 0,915 & 0,846 & 0,690 & 0,536 & 0,621 & 0,667 & 0,809 & 0,902 & 0,967 \\
\hline \multirow{3}{*}{$\begin{array}{l}\text { ESTkg } \\
(\mathrm{kg} / \mathrm{d})\end{array}$} & 1 & 3,775 & 4,077 & 4,258 & 4,067 & 4,011 & 3,941 & 3,732 & 3,455 & 3,257 & 3,022 \\
\hline & 2 & 3,539 & 3,653 & 3,603 & 3,396 & 3,365 & 3,235 & 3,084 & 2,994 & 2,789 & 2,515 \\
\hline & $P<$ & 0,426 & 0,246 & 0,112 & 0,061 & 0,036 & 0,021 & 0,015 & 0,015 & 0,015 & 0,015 \\
\hline \multirow{3}{*}{$\begin{array}{l}\mathrm{EST} \% \\
(\%)\end{array}$} & 1 & 12,38 & 12,18 & 12,13 & 12,09 & 12,04 & 12,03 & 12,03 & 12,05 & 12,06 & 12,08 \\
\hline & 2 & 12,51 & 12,45 & 12,37 & 12,26 & 12,23 & 23,25 & 12,28 & 12,33 & 12,37 & 12,38 \\
\hline & $P<$ & 0,623 & 0,334 & 0,403 & 0,520 & 0,455 & 0,364 & 0,296 & 0,222 & 0,174 & 0,177 \\
\hline \multirow{3}{*}{$\begin{array}{l}\text { ESDkg } \\
(\mathrm{kg} / \mathrm{d})\end{array}$} & 1 & 2,616 & 2,869 & 2,984 & 2,869 & 2,805 & 2,750 & 2,790 & 2,439 & 2,291 & 2,138 \\
\hline & 2 & 2,490 & 2,578 & 2,575 & 2,461 & 2,464 & 2,275 & 2,157 & 2,094 & 1,945 & 1,754 \\
\hline & $P<$ & 0,548 & 0,305 & 0,159 & 0,106 & 0,086 & 0,056 & 0,043 & 0,038 & 0,035 & 0,033 \\
\hline \multirow{3}{*}{$\begin{array}{l}\mathrm{ESD} \% \\
(\%)\end{array}$} & 1 & 8,54 & 8,47 & 8,46 & 8,45 & 8,41 & 8,40 & 8,39 & 8,41 & 8,42 & 8,44 \\
\hline & 2 & 8,81 & 8,78 & 8,76 & 8,72 & 8,74 & 8,72 & 8,72 & 8,74 & 8,75 & 8,75 \\
\hline & $P<$ & 0,076 & 0,035 & 0,030 & 0,029 & 0,005 & 0,004 & 0,002 & 0,001 & 0,001 & 0,001 \\
\hline
\end{tabular}

${ }^{1}$ Classe 1: escore de condição corporal ao parto $\geq 3,25$ (média ECCP=3,41).

${ }^{2}$ Classe 2: escore de condição corporal ao parto $<3,25$ (média $\mathrm{ECCP}=2,75$ ).

${ }^{3}$ Nível de significância.

Estes resultados são semelhantes aos descritos por Pedron et al. (1993), Waltner et al. (1993) e Domecq et al. (1997), que verificaram maior PL e PLC nas vacas com ECCP próximo a 3,5. Segundo Gallo et al. (1996), vacas com maior ECCP mobilizam maior quantidade de reservas corporais pós-parto, o que contribuiu para o fornecimento de nutrientes para a produção de leite no início da lactação (Bauman e Currie, 1980; Bell, 1995; Tamminga et al., 1997).

Foram observadas diferenças na produção e na porcentagem de gordura entre as classes de ECCP (Tab. 2 e 3). As vacas primíparas da classe 1 apresentaram maior $\operatorname{Gkg}(\mathrm{P}=0,10)$ e $\mathrm{G} \%$ $(\mathrm{P}<0,05)$ em relação às da classe 2 . No entanto, as multíparas da classe 1 apresentaram maior
Gkg $(\mathrm{P}<0,05)$ e similar $\mathrm{G} \%(\mathrm{P}>0,05)$ em relação às multíparas da classe 2 .

Não foi observada diferença na porcentagem de gordura entre vacas multíparas das classes 1 e 2 em decorrência do balanço energético negativo pós-parto semelhante, ou da semelhança na dieta das duas classes. As multíparas da classe 1, porém, apresentaram maior $\mathrm{Gkg}$, atribuída ao fato de a porcentagem de gordura do leite ser semelhante e a produção de leite ser maior.

Maior $\mathrm{G} \%$ nas vacas primíparas da classe 1 pode estar relacionada à mobilização de reservas corporais em vacas com maior ECCP, resultando numa grande liberação de ácidos graxos nãoesterificados (AGNE), provenientes do tecido 
adiposo para a circulação sangüínea (Bell, 1995). Essa liberação pode contribuir para o aumento do pool de ácidos graxos que formam a gordura do leite, favorecendo a captura de ácidos graxos de cadeia longa do sangue para a glândula mamária, resultando na grande incorporação deles ao leite de vacas nas primeiras 12 semanas pós-parto (Palmquist et al., 1993).

Nas vacas primíparas (Tab. 2), não foram observados efeitos do ECCP sobre ESTkg e ESDkg e sobre EST\% $(\mathrm{P}>0,05)$. Contudo, verificou-se maior EST\% nas vacas da classe 1 . Nas multíparas (Tab. 3), não foram verificadas alterações em relação à EST\% $(\mathrm{P}>0,05)$, sendo, no entanto, verificado maior ESTkg $(\mathrm{P}<0,05)$ para as vacas da classe 1 . Observou-se maior ESDkg nas multíparas da classe $1 \quad(\mathrm{P}<0,05)$ e maior ESD\% nas multíparas da classe 2 $(\mathrm{P}=0,06)$. Apesar da maior $\mathrm{ESD} \%$ nas vacas da classe 2 , a diferença de $+19,9 \%$ na PL nas vacas da classe 1 resultou em maior ESDkg nesses animais.

Estes resultados são semelhantes aos relatados por Pedron et al. (1993), Waltner et al. (1993) e
Domecq et al. (1997), que verificaram maior produção de leite e de seus componentes em vacas que ao parto apresentaram ECC entre 3,25 a 3,75, quando comparadas a vacas de ECC ao parto $<3,0$. Dessa forma, os resultados deste estudo sugerem que as recomendações de ECCP ideal, descritas por Edmonson et al. (1989) e Ferguson et al. (1994), também podem ser adotadas em rebanhos brasileiros.

$\mathrm{Na}$ Fig. 1, são apresentadas as equações de regressão, os coeficientes de determinação e as curvas de lactação da PL e da PLC, para vacas primíparas e multíparas. Nas primíparas da classe 1, verificou-se que a PL e a PLC diminuíram após os primeiros 15 dias de lactação, persistindo até o final do período avaliado, sendo evidenciado pelo comportamento linear decrescente da curva de lactação estimada. A PLC das vacas primíparas da classe 2 apresentou o mesmo comportamento. No entanto, na PL das primíparas da classe 2, verificou-se comportamento quadrático na curva de lactação, estimando-se a máxima produção de leite aos 47,5 dias de lactação.
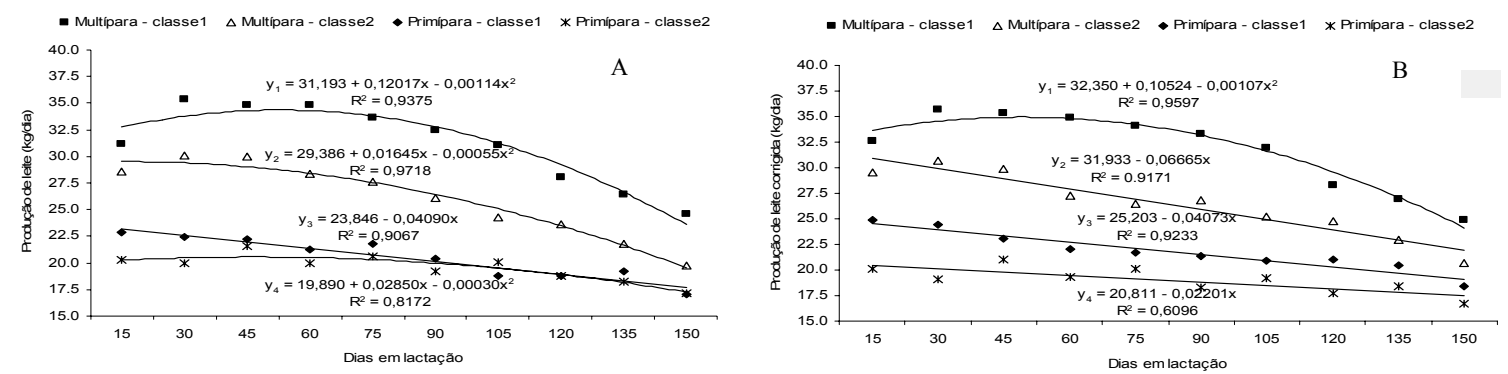

Figura 1. Curva de lactação da produção de leite $(\mathrm{kg} /$ dia) $(\mathrm{A})$ e produção de leite corrigida para $3,5 \%$ de gordura (kg/dia) (B) até os 150 dias de lactação, segundo a condição corporal ao parto, para primíparas e multíparas.

Em vacas de primeiro parto, segundo o NRC (Nutrient..., 2001), espera-se que a curva de lactação apresente pico de produção menos evidente e maior persistência de lactação do que em vacas multíparas, justificando o comportamento linear das curvas de lactação estimadas para a PL e da PLC. Em relação à PL das vacas multíparas da classe 2 , o coeficiente de determinação foi menor, o que demonstra que os fatores incluídos no modelo explicaram pequena proporção da variabilidade na característica. As da classe 1 apresentaram maior média de produção de leite, especialmente a PLC.

As vacas multíparas apresentaram evidente pico de produção de leite, demonstrando o comportamento curvilíneo das equações estimadas para a PL e a PLC, conforme citou o NRC (Nutrient..., 2001). No entanto, a equação estimada para a PLC das vacas da classe 2 apresentou comportamento linear. As da classe 1 (Fig. 1) apresentaram maior média de PL e pico de lactação posterior aos animais da classe 2 
(52,7 × 14,9 dias de lactação, respectivamente). Em relação à PLC (Fig. 1), devido à maior porcentagem de gordura no início de lactação em ambas as classes de ECCP (Fig. 2), o pico de produção de leite foi antecipado para 49,2 dias nas vacas da classe 1 . Nas vacas da classe 2 , o comportamento da curva de lactação da PLC passou a ser linear.
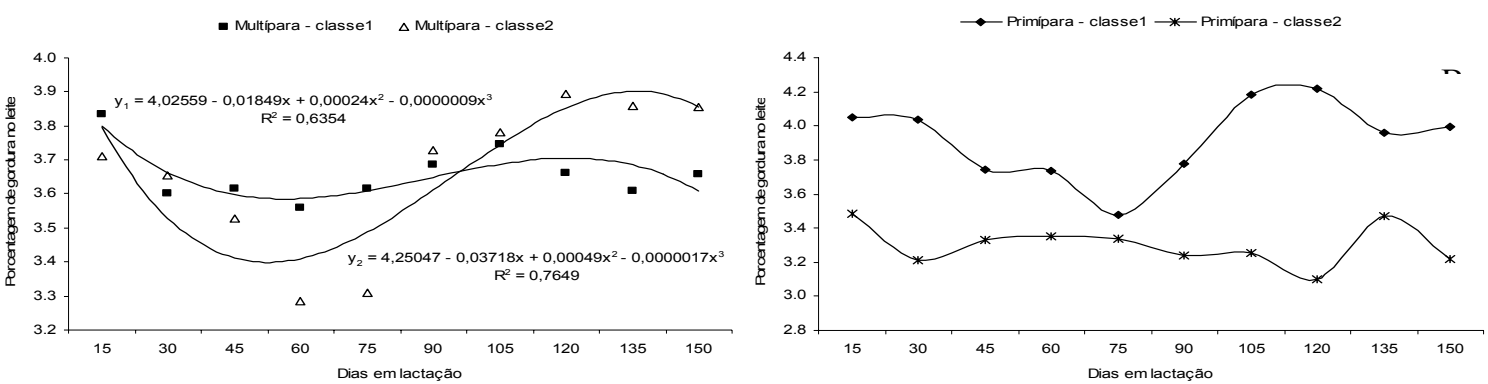

Figura 2. Curva de lactação da porcentagem de gordura do leite (\%) até os 150 dias de lactação, segundo a condição corporal ao parto, para multíparas (A) e primíparas (B).

A equação estimada para a $\mathrm{G} \%$ apresentou comportamento cúbico para as vacas multíparas de ambas as classes de ECCP. Não foram ajustadas equações para as vacas primíparas em função da grande variabilidade na $\mathrm{G} \%$ do início da lactação (Fig. 2). Nas multíparas, apesar de serem ajustadas equações para a $\mathrm{G} \%$, também se observa (Fig. 2) grande variabilidade na porcentagem de gordura.

A maior porcentagem de gordura no início da lactação representa variações na magnitude do balanço energético negativo pós-parto $\mathrm{e}$ conseqüente contribuição das reservas corporais para a síntese de gordura no leite nessa fase da lactação (Palmquist et al., 1993). O comportamento cúbico das equações ajustadas possivelmente reflete ajustes de manejo ou fatores dietéticos que influenciaram a síntese de gordura do leite nas multíparas de ambas as classes, como alterações da proporção volumoso:concentrado nas rações fornecidas aos animais durante a lactação (Grummer et al., 1991).

Butler e Smith (1989) relataram que as reservas corporais podem contribuir significativamente para a produção de leite e gordura no início da lactação. Dessa forma, quando vacas leiteiras, principalmente multíparas, apresentarem adequado ECCP $(3,25$ a 3,75$)$, a curva de lactação mostrará maior pico de produção e maior persistência de lactação em relação às vacas de baixo ECCP $(<3,0)$. Pedron et al. (1993) verificaram resultados semelhantes. Vacas com ECCP de 3,5 a 4,0 apresentaram curvas de lactação com maior pico de produção e maior persistência de lactação, em relação às com ECCP menor ou igual a 3,0.

O resumo das análises de variância e as médias do ECC e da MECC podem ser observados na Tab. 4 e na Fig. 3. A ordem de partos não influenciou o ECC e a MECC ao longo da lactação, demonstrando padrão similar de modificações no ECC no início da lactação nas vacas primíparas e multíparas. Foi observado o padrão de mobilização de reservas corporais no ínício da lactação descrito por Waltner et al. (1993) e Gallo et al. (1996), para vacas de diferentes ordens de parto.

Tabela 4. Níveis de significância dos fatores incluídos nas análises de variância do escore da condição corporal (ECC) e da mudança de condição corporal (MECC), nas vacas primíparas e multíparas

\begin{tabular}{|c|c|c|c|c|}
\hline \multirow{3}{*}{ Variável } & \multicolumn{4}{|c|}{ Valor de $\mathrm{P}$} \\
\hline & \multicolumn{2}{|c|}{ Primíparas } & \multicolumn{2}{|c|}{ Multíparas } \\
\hline & ECC & MECC & ECC & MECC \\
\hline Grupo $^{1}$ & 0,2399 & 0,1573 & 0,0002 & $<0,0001$ \\
\hline Tempo $^{2}$ & $<0,0001$ & $<0,0001$ & $<0,0001$ & $<0,0001$ \\
\hline Grupo x Tempo & 0,1665 & 0,4614 & 0,0003 & 0,0006 \\
\hline
\end{tabular}



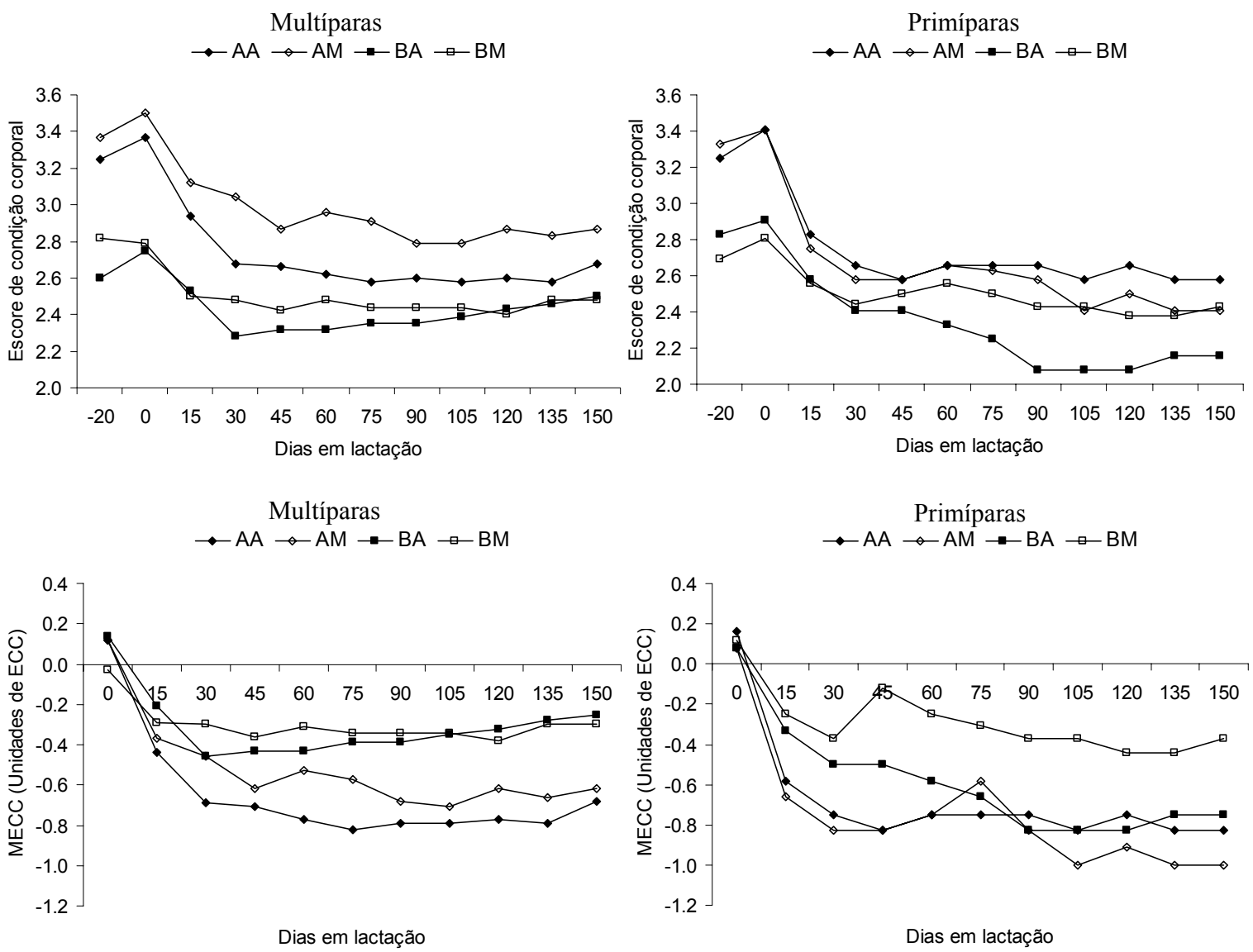

Figura 3. Escore de condição corporal e mudança do escore de condição corporal (MECC), para vacas multíparas (A e C) e primíparas (B e D), em função do grupo avaliado (combinação do escore de condição corporal ao parto (ECCP) e do nível de produção). $\mathrm{AA}=\mathrm{ECCP} \geq 3,25$ e alta produção; $\mathrm{AM}=\mathrm{ECCP} \geq 3,25$ e média produção; $\mathrm{BA}=\mathrm{ECCP}<3,25$ e alta produção; $\mathrm{BM}=\mathrm{ECCP}<3,25$ e média produção. Média de produção de leite corrigida para 3,5\% de gordura ( $\mathrm{kg} / \mathrm{dia})$, aos 150 dias pós-parto: primíparas $-\mathrm{AA}=24,60 ; \mathrm{AM}=19,26 ; \mathrm{BA}=24,16 ; \mathrm{BM}=15,32 ;$ multíparas $-\mathrm{AA}=34,97 ; \mathrm{AM}=25,91$; $\mathrm{BA}=32,04 ; \mathrm{BM}=23,77$.

Os grupos avaliados (ECCP x nível de produção de leite) não influenciaram $(\mathrm{P}>0,05)$ o $E C C$ e a MECC durante a lactação nas vacas primíparas, possivelmente pela menor diferença entre as médias de produção entre os grupos avaliados $(24,38 \times 17,29 \mathrm{~kg} / \mathrm{dia}$, para o nível alto e médio de produção, respectivamente) e pelo número de animais avaliados (13 primíparas). O ECCP influenciou o ECC médio no início da lactação quando comparados ao nível alto de produção. Vacas que apresentaram maior ECCP também mantiveram maior condição corporal próximas dos 100 dias de lactação (Fig. 3), refletindo semelhante MECC nos animais de primeiro parto no nível alto de produção (grupos AA e BA).
No nível médio de produção, os animais apresentaram ECC semelhante durante a lactação quando se compararam vacas de alto e baixo ECCP (grupos AM e BM, respectivamente), mas em relação à $\mathrm{MECC}$, os animais de maior ECCP apresentaram mobilização mais acentuada de suas reservas corporais para a sustentação da produção no início da lactação.

Os grupos avaliados (AA, AM, BA e BM, respectivamente, classe 1 e alta produção, classe 1 e média produção, classe 2 e alta produção, e classe 2 e média produção), nas vacas multíparas, influenciaram o ECC $(\mathrm{P}<0,05)$ durante a lactação. As vacas da classe 1 
apresentaram maior ECC do que as da classe 2 . Em relação ao nível de produção, as vacas de menor produção de leite, independentemente do ECCP, apresentaram maior ECC no início da lactação (Fig. 3) do que as de maior produção.

Também foi verificado efeito dos grupos avaliados $(\mathrm{P}<0,05)$ sobre a MECC. As vacas da classe 1 apresentaram maior mobilização das reservas corporais, independentemente do nível de produção, o que resultou em redução de $-0,68$ e $-0,62$ unidades de ECC, do parto até 150 dias de lactação. No entanto, as vacas da classe 2 apresentaram mobilização de somente $-0,25$ e $-0,30$ unidades de ECC no mesmo período (Fig. 3).

Em relação à avaliação da MECC nas vacas de alta e média produção, é interessante ressaltar que os animais de alta produção apresentaram queda mais acentuada no ECC após o parto, evidenciada pela interação $(\mathrm{P}<0,05)$ entre os efeitos de grupo $\times$ tempo (Tab. 4), situação não apresentada pelas vacas de média produção, independentemente do ECCP. No entanto, se forem avaliadas as médias de MECC ao final de 150 dias de lactação, verifica-se que elas são semelhantes quando avaliadas por classe de ECCP, demonstrando similar magnitude total do balanço energético negativo pós-parto, apesar da menor intensidade do balanço energético negativo nas primeiras semanas pós-parto nas vacas de menor produção, demonstrada pela lenta diminuição do ECC.

As equações de regressão do ECC nos 150 primeiros dias da lactação, segundo os grupos de ECCP e produção de leite, para vacas primíparas e multíparas, são apresentadas na Tab. 5. O ECC decresceu, apresentando comportamento curvilíneo nas vacas primíparas de maior produção, com menor condição corporal aos 101,6 e 113,8 dias, para animais da classe 1 e 2 , respectivamente. Nas vacas de menor produção, o ECC decresceu, linearmente ao longo da lactação, demonstrando que mobilizaram continuamente suas reservas corporais, apesar da menor produção. Nas vacas multíparas da classe 1, o ECC apresentou comportamento curvilíneo, com menor condição corporal aos 96,6 e 103,5 dias para vacas de alta e média produção, respectivamente. O ECC das vacas multíparas da classe 2 decresceu, apresentando comportamento curvilíneo, com menor condição corporal aos 80,6 e 92,9 dias de lactação, respectivamente, para as vacas de alta e média produção, demonstrando que a mobilização de reservas corporais foi menos prolongada do que nas vacas da classe 1 .

Tabela 5. Equações de regressão do escore de condição corporal e do peso corporal em função de dias em lactação (parto até 150 dias), segundo os grupos de escore de condição corporal ao parto e produção de leite

\begin{tabular}{llcc}
\hline Grupo & \multicolumn{1}{c}{ Equação de regressão } & Valor de $P$ & $\mathrm{R}^{2} / \mathrm{r}^{2}$ \\
\hline Classe 1, alta produção & Escore de condição corporal - Primíparas & 0,0467 & 66,50 \\
Classe 1, média produção & $\hat{Y}=3,15863-0,01209 d+0,00005958 d^{2}$ & 0,0109 & 53,16 \\
Classe 2, alta produção & $\hat{Y}=2,96968-0,00424 d$ & $<0,0001$ & 94,55 \\
Classe 2, média produção & $\hat{Y}=2,85025-0,01314 d+0,00005772 d^{2}$ & 0,0350 & 44,55 \\
& $\hat{Y}=2,66783-0,00208 d$ & & 84,99 \\
Classe 1, alta produção & Escore de condição corporal - Multíparas & 0,0004 & 86,67 \\
Classe 1, média produção & $\hat{Y}=3,21932-0,01449 d+0,00007500 d^{2}$ & 0,0003 & 70,61 \\
Classe 2, alta produção & $\hat{Y}=3,38409-0,01139 d+0,00005505 d^{2}$ & 0,0075 & 67,72 \\
Classe 2, média produção & $\hat{Y}=2,65015-0,00845 d+0,00005245 d^{2}$ & 0,0109 & 55,08 \\
Classe 1, alta produção & $\hat{Y}=2,68033-0,00589 d+0,00003174 d^{2}$ & 0,0407 & 54,45 \\
Classe 1, média produção & $\hat{Y}=618,81601-0,58945 d+0,00329 d^{2}$ & 0,0430 & 39,96 \\
Classe 2, alta produção & $\hat{Y}=577,89045-0,76746 d+0,00407 d^{2}$ & 0,1299 & 71,97 \\
Classe 2, média produção & $\hat{Y}=571,79980-0,33752 d+0,00277 d^{2}$ & 0,0062 &
\end{tabular}


Segundo Smith e McNamara (1990), vacas de alto mérito genético para produção de leite apresentam diminuição da resposta do tecido adiposo aos agentes antilipolíticos, resultando em aumento das taxas de lipólise. De forma semelhante, Rukkwamsuk et al. (1998) e Rukkwamsuk et al. (1999) demonstraram que vacas de maior ECC apresentam maior massa corporal na forma de gordura e, assim como vacas de alto mérito genético para produção de leite, também apresentam reduzida resposta do tecido adiposo ao estímulo antilipolítico, o que também vai resultar em aumento das taxas de lipólise e maior mobilização de reservas corporais.

Ainda, segundo McNamara et al. (1995), vacas com maior ECC apresentam maior tamanho do adipócito, que está relacionado com maior resposta do tecido adiposo frente aos estímulos lipolíticos (Vernon e Finley, 1985). Katamoto et al. (1996) avaliaram a resistência à insulina, conhecido agente antilipolítico (Bell, 1995), em adipócitos de vacas de baixo (magras) e alto (gordas) ECC, e verificaram que vacas gordas apresentam maior resistência à insulina, o que contribui para a maior taxa de lipólise. Dessa forma, vacas de alta produção e de maior ECCP apresentam modificações no metabolismo que vão alterar as taxas de lipólise e de lipogênese (efeito antilipolítico). Essas alterações resultam em aumento das taxas de lipólise, ocorrendo intensa mobilização de reservas corporais e redução do ECC em vacas leiteiras.

Gallo et al. (1996) e Aeberhard et al. (2001) verificaram maiores médias de ECC durante a lactação em vacas de menor nível de produção, enquanto Pedron et al. (1993), Berry et al. (2002) e Dechow et al. (2002) verificaram maior ECC ao longo da lactação em vacas que apresentaram maior ECCP. Quando foram avaliados conjuntamente o nível de produção de leite e o ECCP, de forma semelhante ao verificado por Ruegg e Milton (1995), foram verificadas maiores médias de MECC em vacas de maiores produções e ECCP. Dessa forma, os resultados deste estudo confirmam os relatados na literatura, quando são avaliados os efeitos do ECCP e do nível de produção sobre a mobilização de reservas corporais em vacas leiteiras no início da lactação.
Na Tab. 6 e na Fig. 4, são apresentados, respectivamente, os resumos das análises de variância e as médias do peso corporal (PC) e da mudança de peso corporal (MPC) nos períodos pré-parto e pós-parto. A média de peso antes do parto foi de $679,4 \mathrm{~kg}$. Na Tab. 5, encontram-se as equações de regressão do $\mathrm{PC}$ nos 150 primeiros dias da lactação, segundo os grupos de ECCP e nível de produção de leite.

Tabela 6. Níveis de significância dos fatores incluídos nas análises de variância do peso corporal (PC) e da mudança de peso corporal (MPC), nos períodos pré-parto e pós-parto

\begin{tabular}{lcccc}
\hline \multirow{2}{*}{ Variável } & \multicolumn{4}{c}{ Valor de $P$} \\
\cline { 2 - 5 } & \multicolumn{2}{c}{ Pré-parto $^{1}$} & \multicolumn{2}{c}{ Pós-parto } \\
\cline { 2 - 5 } & PC & MPC & PC & MPC \\
\hline Grupo $^{2}$ & $\mathbf{0 , 0 0 0 4}$ & 0,7649 & $\mathbf{0 , 0 4 2 5}$ & 0,4232 \\
Tempo $^{3}$ & $<0,0001$ & $<0,0001$ & 0,0049 & 0,0054 \\
Grupo x tempo $^{4}$ & 0,2111 & 0,1304 & 0,6706 & 0,7277 \\
Idade $^{4}$ & 0,0004 & - & 0,0003 & - \\
Peso -20 $^{5}$ & - & 0,0028 & - & - \\
Peso 0 $^{5}$ & - & - & - & 0,0740 \\
\hline
\end{tabular}

${ }^{1}$ Inclui o dia do parto.

2 Grupo: combinações das classes de ECCP e nível de produção

${ }^{3}$ Tempo: dias em lactação.

${ }^{4}$ Covariável idade da vaca ao parto.

${ }^{5}$ Covariáveis -20 e 0 são o peso aos 20 dias pré-parto e o peso após o parto, respectivamente.

Não foram observadas diferenças no peso corporal entre as vacas de diferentes níveis de produção de leite. Nas vacas de alta produção, os animais da classe 1 apresentaram maior peso préparto e no dia do parto $(\mathrm{P}<0,05)$ em relação aos animais da classe 2 . Os do grupo AA pesaram ao parto $40,4 \mathrm{~kg}$ a mais do que os animais do grupo BA. No entanto, no período pós-parto, não foram verificadas diferenças entre os animais dos dois grupos. Nas vacas de média produção (AM e $\mathrm{BM}$ ), não foram observadas diferenças entre os grupos em relação ao $\mathrm{PC}$, período avaliado.

$\mathrm{Na}$ avaliação da MPC, não foram verificadas diferenças entre os grupos nos períodos préparto, no dia do parto e no pós-parto. A MPC no período pós-parto foi maior para os animais dos grupos AA e AM, apesar de estatisticamente não diferirem dos grupos BA e BM (Fig. 4).

O PC no período pós-parto seguiu o padrão descrito por Koenen et al. (1999) e Buckley et al. (2000). Os animais apresentaram média de perda de peso ao parto de $77,3 \mathrm{~kg}$, refletindo a expulsão do feto, placenta e demais conteúdos uterinos, e o início do catabolismo de reservas corporais, 
representando $11,4 \%$ do peso vivo. No período pós-parto, foi observada rápida diminuição no peso corporal, com valor mínimo estimado, segundo as equações de regressão descritas na Tab. 4, aos 89,6, 94,3, 60,9 e 81,2 dias, para os grupos AA, AM, BA e BM, respectivamente. Essa mudança do PC, segundo Komaragiri et al. (1998), reflete primariamente o intenso catabolismo de reservas corporais para o fornecimento de energia para a produção de leite no início da lactação.

Em relação ao PC pré-parto e ao parto, os resultados deste estudo assemelham-se aos de Holter et al. (1990), que verificaram maior peso corporal ao parto para vacas de maior ECCP. Apesar de as vacas deste estudo serem selecionadas em função do peso 30 dias préparto, com a proximidade do parto e com o ganho de peso durante o período seco, as de maior ECCP apresentaram PC pré-parto e ao parto mais elevado.

Neste estudo, não foram verificadas diferenças significativas em relação à MPC para vacas de maior ECCP, apesar de os animais da classe 1 apresentarem maior perda de peso, diferindo dos resultados apresentados por Holter et al. (1990) e Berry et al (2002), os quais verificaram maior perda de peso pós-parto para vacas de maior ECCP. Esses autores associaram maior MPC à maior mobilização de reservas corporais no início da lactação.

No entanto, segundo Chilliard et al. (1991) e Nutrient... (2001), a MPC pode não refletir adequadamente a mobilização de reservas corporais no início da lactação. Andrew et al. (1994) verificaram que vacas leiteiras podem alterar a composição corporal no início da lactação, mobilizando cerca de $40 \%$ de suas reservas corporais, apresentando, porém, pequena ou nenhuma variação no peso corporal. Devido aos rápidos aumentos no consumo de matéria seca e produção de leite e da simultânea mobilização de reservas corporais pós-parto, alterações do peso corporal podem ser influenciadas pelo enchimento do trato gastrintestinal, fazendo com que as variações no peso corporal não reflitam adequadamente a mobilização de reservas corporais (Andrew et al., 1994; Nutrient..., 2001). Assim, os resultados deste estudo, em relação ao ECCP e à variação no peso corporal, justificam-se.

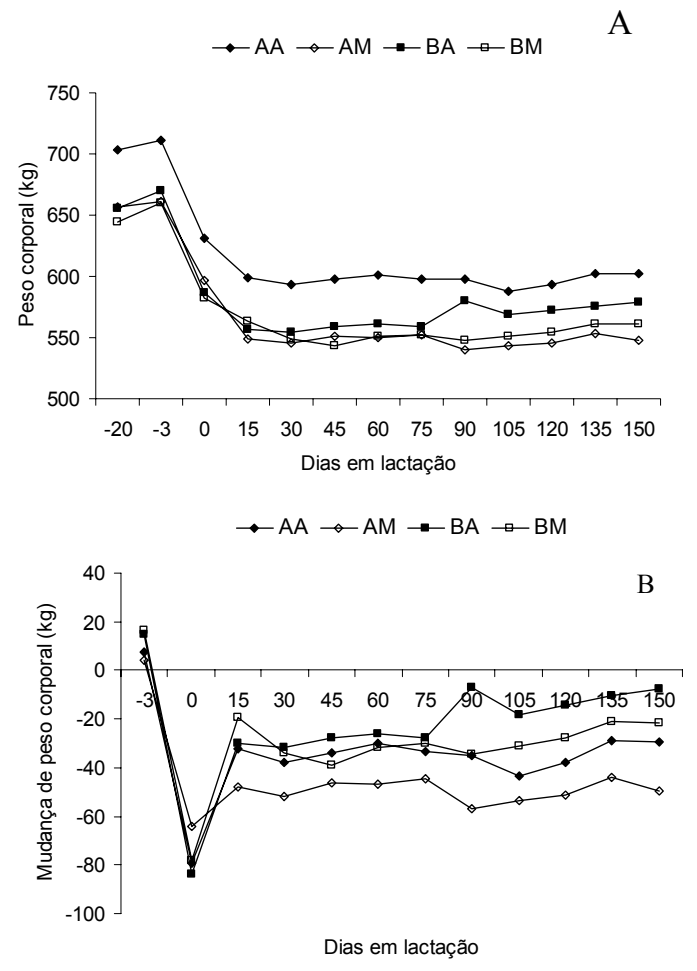

Figura 4. Peso corporal (A) e mudança do peso corporal (B) em função do grupo avaliado (combinação do escore de condição corporal ao parto (ECCP) e do nível de produção). $\mathrm{AA}=\mathrm{ECCP} \geq 3,25$ e alta produção; $\mathrm{AM}=\mathrm{ECCP}$ $\geq 3,25$ e média produção; $\mathrm{BA}=\mathrm{ECCP}<3,25$ e alta produção; $\mathrm{BM}=\mathrm{ECCP}<3,25$ e média produção. Média de produção de leite corrigida para 3,5\% de gordura (kg/dia), aos 150 dias pós-parto: grupos $\mathrm{AA}=33,32 ; \quad \mathrm{AM}=22,70 ; \quad \mathrm{BA}=31,13$; $\mathrm{BM}=22,72$. ) Os dias $-20,-3$ e 0 se referem, respectivamente, aos dias 20 e 3 antes do parto e ao dia do parto (primeiras 24 horas).

\section{CONCLUSÕES}

Vacas com escore de condição corporal ao parto próximo a 3,5 apresentam melhores condições de expressarem maior produção de leite e de seus componentes, refletindo em curvas de lactação com maior pico de produção e persistência, especialmente as multíparas. As recomendações de escore de condição corporal adequado ao parto para maximização da produção são de 3,25 a 3,75. Vacas leiteiras de maior produção de leite 
e de escore de condição corporal ao parto adequado são mais susceptíveis a apresentarem extensa mobilização de reservas corporais, demonstrando a necessidade de atenção nos programas de alimentação para que não apresentem problemas de saúde decorrentes do excesso de mobilização de reservas corporais pós-parto. Apesar de diferenças no desempenho e no padrão de mobilização de reservas corporais, o peso corporal e a mudança de peso corporal não se alteram quando se avaliam vacas de diferentes escores de condição corporal ao parto e níveis de produção de leite, especialmente no pós-parto, demonstrando que a utilização do peso e da mudança de peso corporal para avaliação da mobilização de reservas corporais no início da lactação não é adequada.

\section{REFERÊNCIAS BIBLIOGRÁFICAS}

AEBERHARD, K.; BRUKMAIER, R.M.; KUEPFER, U. et al. Milk yield and composition, nutrition, body conformation traits, body condition scores, fertility and diseases in high-yielding dairy cows - Part 1. J. Vet. Med. A, v.48, p.97-110, 2001.

ANDREW, S.M.; WALDO, D.R.; ERDMAN, R.A. Direct analysis of body condition of dairy cows at three physiological stages. J. Dairy Sci., v.77, p.3022-3033, 1994.

BAUMAN, D.E.; CURRIE, W.B. Partitioning of nutrients during pregnancy and lactation: a review of mechanisms involving homeostasis and homeorhesis. J. Dairy Sci., v.62, p.1514-1528, 1980.

BELL, A.W. Regulation of organic nutrient metabolism during transition from late pregnancy to early lactation. J. Anim. Sci., v.73, p.2804-2819, 1995.

BERRY, D.P.; BUCKLEY, F.; DILLON, P. et al. Genetic parameters for level and change of body condition score and body weight in dairy cows. $J$. Dairy Sci., v.85, p.2030-2039, 2002.

BUCKLEY, F.; DILLON, P.; RATH, M. et al. The relationship between genetic merit for yield and live weight, condition score, and energy balance of spring calving Holstein-Friesian cows on grass based systems of milk production. J. Dairy Sci., v.83, p.1878-1886, 2000.

BUTLER, W.R.; SMITH, R.D. Interrelationships between energy balance and post-partum reproductive function in dairy cattle. J. Dairy Sci., v.72, p.767-783, 1989.

CHILLIARD, Y.; CISSÉ, M.; LEFAIFRE, R. et al. Body composition of dairy cows according to lactation stage, somatotropin treatment, and concentrate supplementation. J. Dairy Sci., v.74, p.3103-3116, 1991.

DECHOW, C.D.; ROGERS, G.W.; CLAY, J.S. Heritability and correlations among body condition score loss, body condition score, production and reproductive performance. J. Dairy Sci., v.85, p.3062-3070, 2002.

DOMECQ, J.J.; SKIDMORE, A.L.; LLOYD, J.W. et al. Relationship between body condition scores and milk yield in a large herd of high yielding Holstein cows. J. Dairy Sci., v.80, p.101-112, 1997.

EDMONSON, A.J.; LEAN, I.J.; WEAVER, L.D. et al. A body condition scoring chart for Holstein dairy cows. J. Dairy Sci., v.72, p.68-78, 1989.

ENEVOLDSEN, C.; KRISTENSEN, T. Estimation of body weight from body size measurements and BCS in dairy cows. J. Dairy Sci., v.80, p.19881995, 1997.

FERGUSON, J.D.; OTTO, K.A. Managing body condition in dairy cows. In: CORNELL NUTRITION CONFERENCE FOR FEED MANUFACTURERS, 1989, Ithaca. Proceedings... Ithaca, 1989. p.75-87.

GALLO, L.; CARNIER, P.; CASSANDRO, M. et al. Change in body condition score of Holstein cows as affected by parity and mature equivalent milk yield. J. Dairy Sci., v.79, p.1009-1015, 1996.

GOFF, J. Principais síndromes que acometem as vacas leiteiras no período periparto. In: CURSO NOVOS ENFOQUES NA PRODUÇÃO E REPRODUÇÃO DE BOVINOS, 8., 2004, Uberlândia. Anais... Uberlândia: CONAPEC, 2004. p.381-398.

GRUMMER, R.R. Effect of feed on the composition of milk fat. J. Dairy Sci., v.74, p.32443257, 1991.

HERDT, T.H. Ruminant adaptation to negative energy balance. In: HERDT, T.H. (Ed.). Metabolic disorders of ruminants. Vet. Clin. North Am., v.16, p.215-230, 2000.

HOLTER, J.B.; SLOTNICK, M.J.; HAYES, H.H. et al. Effect of prepartum dietary energy on condition score, postpartum energy, nitrogen partitions, and lactation production responses. $J$. Dairy Sci., v.73, p.3502-3511, 1990. 
KATAMOTO, H.; YUKAWA, T.; SHIMADA, Y. Lipogenic and lipolytic activities in isolated adipocytes from cattle with fat necrosis. Res. Vet. Sci., v.61, p.214-219, 1996.

KOENEN, E.P.C.; GROEN, A.F.; GENGLER, N. Phenotypic variation in live weight and live-weight changes of lactating Holstein-Friesian cows. Anim. Sci., v.68, p.109-114, 1999.

KOMARAGIRI, M.V.S.; CASPER, D.P.; ERDMAN, R.A. Factors affecting body tissue mobilization in early lactation dairy cows. 2 . Effect of dietary fat on mobilization of body fat and protein. J. Dairy Sci., v.81, p.169-175, 1998.

LAGO, E.P.; PIRES, A.V.; SUSIN, I. et al. Efeito da condição corporal ao parto sobre alguns parâmetros do metabolismo energético, produção de leite e incidência de doenças no pós-parto de vacas leiteiras. Rev. Bras. Zootec., v.30, p.15441549, 2001.

McNAMARA, J.P.; HARRISON, J.H.; KINCAID, R.L. et al. Lipid metabolism in adipose tissue of cows fed diets during lactation. J. Dairy Sci., v.78, p.2782-2790, 1995.

NUTRIENT requirements of dairy cattle. 7.ed. Washinton, DC: National Academic, 2001. 381p.

PALMQUIST, D.L.; BEAULIEU, A.D.; BARBANO, D.M. Feed and animal factors influencing milk fat composition. J. Dairy Sci., v.76, p.1753-1771, 1993.

PEDRON, O.; CHELI, F.; SENATORE, E. et al. Effect of body condition score at calving on performance, some blood parameters, and milk fat acid composition in dairy cows. J. Dairy Sci., v.76, p.2528-2535, 1993.

RUEGG, P.L.; MILTON, R.L. Body condition scores of Holstein cows on Prince Edward Island, Canada: Relationship with yield, reproductive performance and disease. J. Dairy Sci., v.78, p.552564, 1995.

RUKKWAMSUK, T.; WENSING, T.; GEELEN, M. J. Effect of overfeeding during the dry period on the rate of esterification in adipose tissue of dairy cows during the periparturient period. J. Dairy Sci., v.82, p.1164-1169, 1999.
RUKKWAMSUK, T.; WENSING, T.; GEELEN, M.J. Effect of overfeeding during the dry period on regulation of adipose tissue metabolism in dairy cows during the periparturient period. J. Dairy Sci., v.81, p.2904-2911, 1998.

SANTOS, J.E.P. Effect of degree of fatness prepartum on lactational performance and follicular development of early lactating dairy cows. 1996. 107f. Dissertation (Master) University of Arizona, Tucson, AR.

SKLAN, D.; KAIM, M.; MOALLEM, U. et al. Effect of dietary calcium soaps on milk yield, body weight, reproductive hormones, and fertility in first parity and older cows. J. Dairy Sci., v.77, p.16521660, 1994.

SMITH, T.R.; McNAMARA, J.P. Regulation of bovine adipose tissue metabolism during lactation. 6. Cellularity and hormone-sensitive lipase activity as affected by genetic merit and energy intake. $J$. Dairy Sci., v.73, p.772-781, 1990.

TAMMINGA, S.; LUTEIJN, P.A.; MEIJER, R.G.M. Changes in composition and energy content of liveweight loss in dairy cows with time after parturition. Livest. Prod. Sci., v.52, p.31-38, 1997.

URBAN, W.E.; McGILLIARD, M.L. Effect of prepartum dietary energy on condition score, postpartum energy, nitrogen partitions and lactating product responses. J. Dairy Sci., v.73, p.3502-3510, 1990.

USER'S guide: statistics. Online Doc. v.8.0, Cary, NC: SAS, Institute, 1999.

VERNON, R.G.; FINLEY, E. Regulation of lipolysis during pregnancy and lactation in sheep. Response to noradrenaline and adenosine. Biochem. J., v.230, p.651-657, 1985.

WALTNER, S.S.; McNAMARA, J.P.; HILLERS, J.K. Relationships of body condition score to production variables in high producing Holstein dairy cattle. J. Dairy Sci., v.66, p.3410-3419, 1993.

WILDMAN, E.E.; JONES, G.M.; WAGNER, P.E. et al. A dairy cow body condition system and its relationship to selected production characteristics. J. Dairy Sci., v.65, p.495-501, 1982. 